\title{
Improving runoff prediction through the assimilation of the ASCAT soil moisture product
}

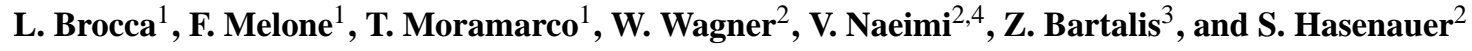 \\ ${ }^{1}$ Research Institute for Geo-Hydrological Protection, National Research Council, Via Madonna Alta 126, 06128 Perugia, Italy \\ ${ }^{2}$ Institute of Photogrammetry and Remote Sensing, Vienna University of Technology, Vienna, Austria \\ ${ }^{3}$ European Space Agency, Centre for Earth Observation (ESA/ESRIN), Via Galileo Galilei, 00044 Frascati, Italy \\ ${ }^{4}$ German Remote Sensing Data Centre, DFD, of the German Aerospace Centre, DLR, Wessling, Germany
}

Received: 14 June 2010 - Published in Hydrol. Earth Syst. Sci. Discuss.: 2 July 2010

Revised: 4 October 2010 - Accepted: 7 October 2010 - Published: 12 October 2010

\begin{abstract}
The role and the importance of soil moisture for meteorological, agricultural and hydrological applications is widely known. Remote sensing offers the unique capability to monitor soil moisture over large areas (catchment scale) with, nowadays, a temporal resolution suitable for hydrological purposes. However, the accuracy of the remotely sensed soil moisture estimates has to be carefully checked. The validation of these estimates with in-situ measurements is not straightforward due the well-known problems related to the spatial mismatch and the measurement accuracy. The analysis of the effects deriving from assimilating remotely sensed soil moisture data into hydrological or meteorological models could represent a more valuable method to test their reliability. In particular, the assimilation of satellite-derived soil moisture estimates into rainfall-runoff models at different scales and over different regions represents an important scientific and operational issue.

In this study, the soil wetness index (SWI) product derived from the Advanced SCATterometer (ASCAT) sensor onboard of the Metop satellite was tested. The SWI was firstly compared with the soil moisture temporal pattern derived from a continuous rainfall-runoff model (MISDc) to assess its relationship with modeled data. Then, by using a simple data assimilation technique, the linearly rescaled SWI that matches the range of variability of modelled data (denoted as $\mathrm{SWI}^{*}$ ) was assimilated into MISDc and the model performance on flood estimation was analyzed. Moreover, three synthetic experiments considering errors on rainfall, model parameters and initial soil wetness conditions were carried out. These experiments allowed to further investi-
\end{abstract}

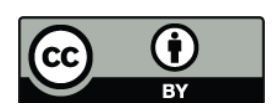

Correspondence to: L. Brocca (1.brocca@irpi.cnr.it) gate the SWI potential when uncertain conditions take place. The most significant flood events, which occurred in the period 2000-2009 on five subcatchments of the Upper Tiber River in central Italy, ranging in extension between 100 and $650 \mathrm{~km}^{2}$, were used as case studies. Results reveal that the SWI derived from the ASCAT sensor can be conveniently adopted to improve runoff prediction in the study area, mainly if the initial soil wetness conditions are unknown.

\section{Introduction}

Soil moisture plays a fundamental role in the partitioning of rainfall into runoff and infiltration inside a catchment. In particular, for a given storm event, different values of initial soil moisture conditions can discriminate between minor or catastrophic flooding effects (see e.g. Crow et al., 2005; Brocca et al., 2008; Berthet et al., 2009; Merz and Bloschl, 2009). Therefore, the assimilation of soil moisture information within rainfall-runoff models can provide, in theory, a great improvement for both runoff prediction and forecasting.

Several studies investigated the use of soil moisture observations within rainfall-runoff models by using, basically, three different methodologies. Some authors directly used these observations for the assessment of the antecedent wetness conditions through in-situ (Meyles et al., 2003; Longobardi et al., 2003; Brocca et al., 2009b; Huang et al., 2007; Pfister et al., 2003; Tramblay et al., 2010; Zehe et al., 2010) and remotely sensed (Jacobs et al., 2003; Goodrich et al., 1994; Brocca et al., 2009a; Beck et al., 2010) estimates. For instance, some studies (Brocca et al., 2009b;

Published by Copernicus Publications on behalf of the European Geosciences Union. 
Tramblay et al., 2010; Beck et al., 2010) investigated the relationship between soil moisture measurements (in-situ and from satellite sensors) and the soil potential maximum retention parameter of the Soil Conservation Service - Curve Number method (Chow et al., 1988) that can be considered a good indicator of the wetness conditions at the catchment scale. Other applications employed soil moisture data for the improvement of the calibration and testing of rainfallrunoff models (Parajka et al., 2006, 2009; Wooldridge et al., 2003; Koren et al., 2008) obtaining that, only in certain conditions, the insertion of soil moisture information can help the model structure identification and parameterization. Finally, sequential data assimilation techniques with in-situ (Loumagne et al., 2001; Aubert et al., 2003; Anctil et al., 2008) and remotely sensed (Crow et al., 2005; Pauwels et al., 2001; 2002; Francois et al., 2003; Matgen et al., 2006; Crow and Ryu, 2009) soil moisture observations were also analyzed. These latter studies showed that, after the assimilation of soil moisture observations, the rainfall-runoff model performance generally increased but, as previously, the enhancement is not so evident (only for one flood event in Francois et al., 2003 and only during high flow conditions in Aubert et al., 2003). The explanation of the little improvements so far obtained by assimilating soil moisture observations can mainly be related to three aspects (see also Vereecken et al., 2008; Crow and Ryu, 2009):

1. the spatial mismatch: the measurement extent is, usually, too low for in-situ data and too coarse for satellite sensors when compared with model quantities;

2. the limited soil moisture data availability: only recently in-situ soil moisture networks are being set up and satellite data with daily, or lower temporal resolution (required for hydrological applications) are becoming available;

3 . the layer depth: remote sensing sensors are able to investigate only a thin surface layer $(2-5 \mathrm{~cm})$ that does not match the soil depth $(1-2 \mathrm{~m})$ usually simulated within rainfall-runoff models.

Notwithstanding these drawbacks, nowadays remote sensing represents the best possible choice for soil moisture monitoring over large areas. In fact, the first satellite mission specifically dedicated to soil moisture monitoring at global scale was just launched on November 2009 (the Soil Moisture and Ocean Salinity, SMOS, mission; Kerr et al., 2001) and another one will be launched in 2015 (the Soil Moisture Active and Passive mission, SMAP, Entekhabi et al., 2008). Additionally, several non-dedicated satellite sensors for soil moisture retrieval are now available (Brocca et al., 2010b). Among them, the Advanced Scatterometer (ASCAT) onboard of the Meteorological Operational (Metop) satellite was found to accurately reproduce the temporal dynamics of in-situ and ground modeled soil moisture observations across different sites in Europe (Albergel et al., 2009; Brocca et al., 2010b). In particular, Brocca et al. (2010b) highlighted the reliability of the soil moisture product derived from the ASCAT sensor when compared with in-situ measurements collected in three experimental areas located in central Italy. The ASCAT sensor, also based on the heritage of the ERS scatterometer, provides an operational soil moisture product on a global scale since January 2007 (Bartalis et al., 2007) with coarse spatial resolution $(25 / 50 \mathrm{~km})$ and nearly daily time scale. Indeed, Sinclair and Pegram (2010), for the South Africa region, compared the soil moisture simulations produced by the rainfall-runoff TOPKAPI (TOPographic Kinematic APproximation and Integration) model to the exponentially filtered time series of the ASCAT surface soil moisture obtaining a good linear agreement in the dynamic behavior of the two independent soil moisture estimates. The authors inferred that the soil moisture fields obtained by the combination of ASCAT satellite data and land surface modeling (TOPKAPI) will be valuable for flash flood guidance and other applications in the region.

Based on the above insights, the main purpose of this study is the assessment of the effects that can be obtained by assimilating the ASCAT soil moisture product in rainfallrunoff modelling. In particular, to our knowledge, this is the first study where coarse resolution satellite data are assimilated into a rainfall-runoff model by using a real data set. In fact, previous studies with real data sets (Pauwels et al., 2001; 2002; Francois et al., 2003; Matgen et al., 2006) considered the assimilation of high resolution SAR (Synthetic Aperture Radar) images that, however, suffer of the wellknown problem of the low revisit time ( $\sim 30$ days). On the other hand, studies using coarse resolution sensors employed satellite data only for rainfall-runoff model calibration (Parajka et al., 2006, 2009) or for the assessment of the reliability of the modeled soil moisture (Sinclair and Pegram, 2010). Moreover, unlike previous studies, the assessment of the benefits (if any) of this assimilation was carried out considering an hourly time scale, which is the appropriate time resolution for operational flood forecasting activities over small to medium catchment sizes $\left(<5000 \mathrm{~km}^{2}\right)$. Specifically, five subcatchments of the Upper Tiber River, ranging in extension between 100 and $650 \mathrm{~km}^{2}$, are used as case studies considering the period January 2007-June 2009 for which ASCAT data are available. A simple data assimilation technique is implemented and the results on runoff prediction with and without the use of ASCAT data are shown. Moreover, three synthetic experiments are also carried out to investigate the effects of the assimilation of ASCAT when errors on rainfall, model parameters or initial conditions take place.

\section{Methods}

In the following, the rainfall-runoff model, the derivation of the satellite soil moisture index and the data assimilation technique are described. The soil moisture product derived 
from ASCAT is represented by a dimensionless index between 0 and 1 and, hence, to be consistent throughout the paper, for it the more appropriate term "saturation degree" is used hereafter, instead of "soil moisture".

\subsection{Rainfall-runoff model}

The continuous rainfall-runoff model, MISDc ("Modello Idrologico SemiDistribuito in continuo"), used in this study was developed by Brocca et al. (2010a) for the simulation of flood events in the Upper Tiber river region at the hourly (or less) time scale. The model consists of two components; the first one is a soil water balance (SWB) model that simulates the saturation degree temporal pattern and sets the initial conditions for the second component which is an event-based rainfall-runoff model for flood hydrograph simulation. By coupling the two components through an experimentally derived relationship between the saturation degree assessed by the SWB model at the start of a flood event and the corresponding antecedent wetness conditions such as expressed by the Soil Conservation Service (Brocca et al., 2009b), the structure of a parsimonious and robust continuous rainfall-runoff model was derived. Specifically, in the SWB model the processes are represented for infiltration through the Green-Ampt equation, for percolation by a gravity driven non-linear relationship and for actual evapotranspiration considering a linear relationship with the potential one, based on a modified Blaney and Criddle approach. For the event-based rainfall-runoff model, the Soil Conservation Service - Curve Number method is employed for computing abstraction from storm rainfall and the Geomorphological Instantaneous Unit Hydrograph for outlet response. It has to be noted that this model structure was developed to simulate discharge only during flood events (not throughout the year) thus reducing the model parameterization and, consequently, the prediction uncertainty.

The model requires, as input data, meteorological variables routinely measured (rainfall and air temperature) and incorporates only 6 parameters to be estimated of which, four parameters refer to the SWB model and the remaining 2 to the event-based rainfall-runoff model. MISDc furnishes, as output, the discharge at the catchment outlet and the saturation degree, $S D$, at the catchment scale for the soil layer influencing the rainfall-runoff transformation, denoted henceforth as "modeled saturation degree", $S D_{\bmod }(t)$. For a detailed description of the model the reader is referred to Brocca et al. (2010a, d).

\subsection{Soil Wetness Index}

The assimilation of remotely sensed saturation degree estimates, representative of a soil layer depth of 2 to $5 \mathrm{~cm}$, into rainfall-runoff models, simulating a layer depth usually greater than $1 \mathrm{~m}$, can be conducted in two different ways: (i) direct insertion of the surface satellite data into the model that, however, should incorporate a surface layer ad hoc implemented for the assimilation (Parajka et al., 2009); (ii) assimilation of a profile soil wetness product obtained by the surface one through the application of an appropriate technique (Parajka et al., 2006; Sinclair and Pegram, 2010). In this study, this latter option was selected and the semiempirical approach (also known as exponential filter) proposed by Wagner et al. (1999a) was adopted for this purpose both for its simplicity and for the request of a single parameter. Briefly, this method assumes that the variation of the average profile saturation degree is linearly related to the difference between the surface and profile saturation degree. For that, the profile saturation degree can be obtained by the knowledge of the surface saturation degree and a parameter $T$, named characteristic time length, representing the time scale of saturation degree variation. The recursive formulation of the method relies on (Albergel et al., 2009):

$\operatorname{SWI}\left(t_{n}\right)=\operatorname{SWI}\left(t_{n-1}\right)+K_{n}\left[m_{\mathrm{S}}\left(t_{n}\right)-\mathrm{SWI}\left(t_{n-1}\right)\right]$

where $m_{\mathrm{S}}\left(t_{n}\right)$ is the surface saturation degree observed by the satellite sensor, $\mathrm{SWI} t_{n}$ is the Soil Wetness Index representing the profile averaged saturation degree and $t_{n}$ is the acquisition time of $m_{\mathrm{s}}\left(t_{n}\right)$. The gain $K_{n}$ at time $t_{n}$ is given by (in a recursive form):

$$
K_{n}=\frac{K_{n-1}}{K_{n-1}+e^{-\left(\frac{t_{n}-t_{n-1}}{T}\right)}}
$$

and it ranges between 0 and 1 . For the initialization of this filter, $K_{1}$ and $\mathrm{SWI}_{1}$ were set to 1 and $m_{\mathrm{S}}\left(t_{1}\right)$, respectively (Albergel et al., 2009).

Prior to the assimilation of SWI $(t)$ into the rainfall-runoff model, a simple linear normalization was conducted through the following equation:

$\operatorname{SWI}^{*}(t)=\left\{\frac{\operatorname{SWI}(t)-\overline{\operatorname{SWI}(t)}}{\sigma[\operatorname{SWI}(t)]}\right\} \sigma\left[S D_{\bmod }(t)\right]+\overline{S D_{\bmod }(t)}$

where $t$ is time, $\mathrm{SWI}^{*}(t)$ is the linearly rescaled $\mathrm{SWI}(t)$, the bar and $\sigma$ are the mean and standard deviation operators and $S D_{\bmod }(t)$ is the modeled saturation degree. The basis of Eq. (3) is to surmise that $\mathrm{SWI}^{*}(t)$ and $S D_{\text {mod }}(t)$ have the same mean and standard deviation. This transformation is required because the exponential filter, Eq. (1), mainly for large $T$ values, has the effect of smoothing the satellite-based surface saturation degree time series. Consequently, the variability range of SWI is no more limited by 0 and 1 as the saturation degree but varies in a narrower range. Moreover, to assimilate the satellite data into the MISDc model, the range of variability of $S D_{\text {mod }}$ and of the ASCAT data has to be the same (Aubert et al., 2003).

\subsection{Data assimilation technique}

In this preliminary study, a very simple approach is employed for the assimilation of the remotely sensed soil wetness index 


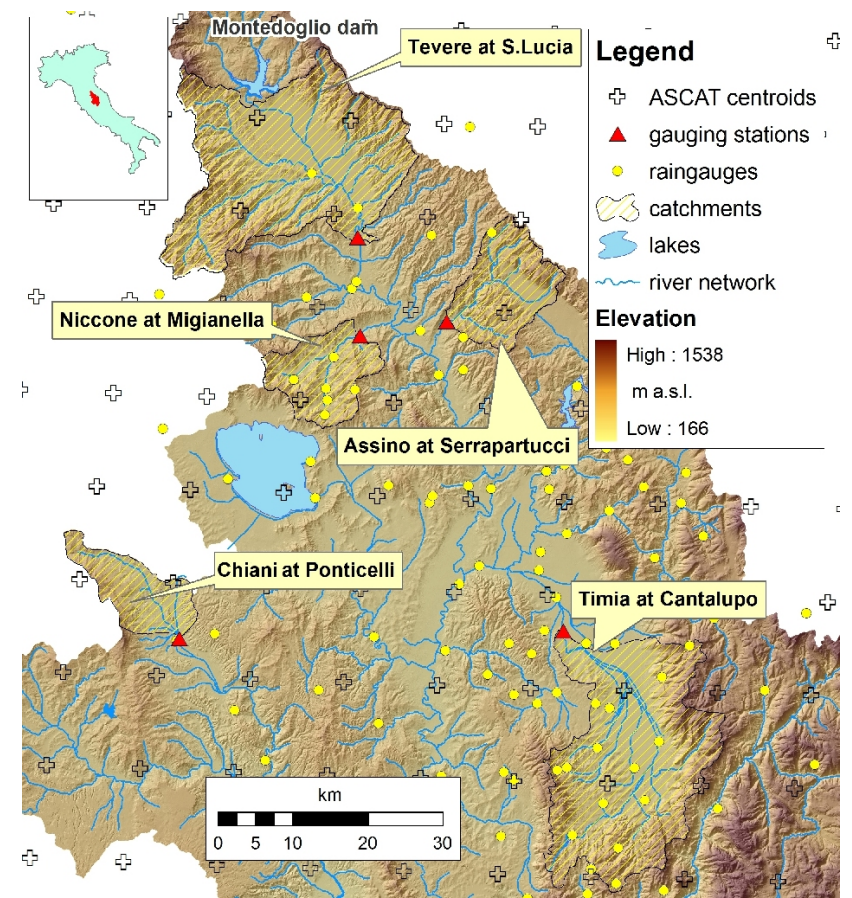

Fig. 1. - Morphology and hydrometeorological network of the study area (Upper Tiber river basin). The five subcatchments analyzed in the study along with the location of the ASCAT pixel centroids are also shown.

into MISDc model. A nudging scheme was used to update the modelled saturation degree, $S D_{\text {mod }}(t)$, when ASCAT observations becomes available:

$$
S D_{\text {ass }}(t)=S D_{\text {mod }}(t)+G\left[\operatorname{SWI}^{*}(t)-S D_{\bmod }(t)\right]
$$

where $t$ is time, $S D_{\text {ass }}(t)$ is the updated modelled saturation degree and $G$ is a constant gain parameter. In practice, $G$ determines the relative weight of the uncertainties on the model prediction against those of remotely sensed saturation degree estimates. In fact, $G$ can be written as (Maybeck, 1979):

$$
G=\frac{\sigma_{S D_{\text {mod }}}^{2}}{\sigma_{S D_{\text {mod }}}^{2}+\sigma_{S W I^{*}}^{2}}
$$

where $\sigma_{S D_{\text {mod }}}^{2}$ and $\sigma_{\mathrm{SWI}^{*}}^{2}$ are the model and the SWI* error variance in the retrieval of saturation degree, respectively. For $G=1$ the observations are assumed right, $\sigma_{\mathrm{SWI}^{*}}^{2}=0$, (direct insertion), vice versa for $G=0$ the model is assumed perfect. Although the nudging scheme employed in this study is not optimal in a statistical sense, it is a computationally inexpensive approach to address the issue on the usefulness of the ASCAT observations to improve runoff prediction (Scipal et al., 2008). In the remainder, for sake of simplicity, the time dependence of $S D_{\text {mod }}(t)$ and $\mathrm{SWI}^{*}(t)$ is omitted.

\begin{tabular}{|c|c|c|c|c|c|}
\hline & \multicolumn{5}{|c|}{ Catchment } \\
\hline & NIC & ASS & $\mathrm{CHI}$ & TEV & TIM \\
\hline drainage area $\left(\mathrm{km}^{2}\right)$ & 137 & 165 & 100 & 658 & 549 \\
\hline mean catchment slope (\%) & 25.0 & 27.6 & 15.0 & 25.9 & 22.6 \\
\hline channel length $(\mathrm{km})$ & 16.4 & 25.2 & 20.1 & 31.0 & 50.9 \\
\hline $\mathrm{N}^{\circ}$ raingauges & 7 & 3 & 2 & 3 & 12 \\
\hline \multicolumn{6}{|c|}{ Hydrologic soil group - Soil Conservation Service (\%) } \\
\hline High infiltration & 3.5 & 9.2 & 7.8 & 8.6 & 43.8 \\
\hline Moderate infiltration rate & 12.7 & 7.9 & 30.1 & 17.5 & 25.4 \\
\hline Low infiltration rate & 83.9 & 81.5 & 51.8 & 71.8 & 28.9 \\
\hline Very low infiltration rate & 0.0 & 1.4 & 10.3 & 2.1 & 1.9 \\
\hline \multicolumn{6}{|c|}{ Land Use (\%) } \\
\hline Woods & 65.0 & 41.8 & 34.0 & 59.8 & 37.1 \\
\hline Croplands & 32.0 & 48.2 & 49.8 & 31.4 & 46.4 \\
\hline Grasslands & 2.7 & 8.9 & 12.6 & 5.9 & 12.0 \\
\hline Urban areas & 0.3 & 1.1 & 3.6 & 2.9 & 4.5 \\
\hline
\end{tabular}

Table 1. - Main characteristics of the five investigated catchments.

\section{Study area and data set}

The study area is the Upper Tiber river catchment that is located in an inland region of Central Italy. In particular, five subcatchments were used to test the assimilation of the ASCAT saturation degree product: Niccone at Migianella (NIC, $137 \mathrm{~km}^{2}$ ), Assino at Serrapartucci (ASS, $165 \mathrm{~km}^{2}$ ), Chiani at Ponticelli (CHI, $100 \mathrm{~km}^{2}$ ), Tevere at S. Lucia (TEV, $658 \mathrm{~km}^{2}$ ) and Timia at Cantalupo (TIM, $549 \mathrm{~km}^{2}$ ). Figure 1 shows the framework of the study area along with the available hydrometeorological network and the centroids of the ASCAT time series. Table 1 reports the main characteristics of each catchment in terms of topography, soil type, land use and hydrometeorological network density.

The climate is Mediterranean with mean annual rainfall of $\sim 950 \mathrm{~mm}$ and ranging over the region between $650 \mathrm{~mm}$ and $1600 \mathrm{~mm}$ (based on the period 1951-1999 and on a network of more than 60 raingauges). Higher monthly rainfall values generally occur during the autumn-winter period when floods occur. Mean annual air temperature (for the same period $1951-1999)$ ranges between $3.5^{\circ} \mathrm{C}$ and $14.0^{\circ} \mathrm{C}$, with maximum in July and minimum in January. Accordingly, the mean annual potential evapotranspiration computed with the Thornthwaite formula is, on average, about $800 \mathrm{~mm}$.

In the study area, a dense hydrometeorological monitoring network ( 1 station every $150 \mathrm{~km}^{2}$ ) has been operating for more than 25 years and the data are recorded with a time interval of $30 \mathrm{~min}$. The existing network consists of 84 rain gauges, 36 thermometers and 43 hydrometric gauges. For this study 10 years of rainfall and temperature data recorded from January 2000 to December 2009 were employed. 


\subsection{ASCAT data set}

Succeeding the ERS-1 and ERS-2 scatterometers, ASCAT is a real-aperture radar instrument measuring radar backscatter at C-band in VV polarization. Because ASCAT operates with two sub-swaths, more than twice of the ERS-1/2 scatterometer coverage is provided. For Western Europe, measurements are generally obtained twice a day, one in the morning (descending orbit) and one in the evening (ascending orbit), between 08:00-11:00 and 17:00-21:00 UTC, respectively. Soil moisture is retrieved from the ASCAT backscatter measurements using a time series-based change detection approach previously developed for the ERS-1/2 scatterometer by Wagner et al. (1999a, b, c). In this approach soil moisture is considered to have a linear relationship to backscatter in the decibel space, while the noise sources include the instrument noise, speckle and azimuthal anisotropies. The surface roughness is assumed to have a constant contribution in time, and therefore is not accounted for in the change detection algorithm. By knowing the typical yearly vegetation cycle and how it influences the backscatter-incidence angle relationship for each location on the Earth, the vegetation effects can be removed (Wagner et al., 1999b), revealing the soil moisture variations. As a last step, the historically lowest and highest values of observed soil moisture are assigned to the $0 \%$ (dry) and $100 \%$ (wet) references respectively, thereby yielding time series of relative soil moisture percentage values for the first few centimeters of the soil.

The surface saturation degree data, $m_{\mathrm{s}}$, used for this study were obtained by processing two years and half (January 2007-June 2009) of $25 \mathrm{~km}$ ASCAT backscatter measurements using the algorithm described by Naeimi et al. (2009). First validation studies of the ASCAT soil moisture product assessed its reliability for estimating both in-situ and ground modeled soil moisture observations across different region in Europe (Albergel et al., 2009; Brocca et al., 2010b) and South Africa (Sinclair and Pregram, 2010) both considering $m_{\mathrm{S}}$ and SWI.

\section{Overall methodology and synthetic data assimilation experiments}

For each catchment, our overall approach is based on the application of the MISDc model to simulate the most significant flood events occurred before the period considered for the assimilation of the ASCAT SWI data (i.e. the period 2000-2007). Then the model is run for the period for which ASCAT data are available (January 2008-June 2009) and $S D_{\text {mod }}$ is compared with the SWI. Afterwards, the SWI is rescaled to match the range of variability of the modeled data through Eq. (3). Thus, the rescaled SWI, SWI*, is assimilated in the MISDc and the outcomes on flood prediction are compared with those without assimilation.
In addition, three synthetic experiments are conducted as follows. Firstly, the rainfall temporal pattern is perturbed through a multiplicative scaling factor sampled from a meanone log-normal distribution with a dimensionless standard deviation of 0.4. Moreover, a possible bias in the rainfall pattern is also analyzed considering a log-normal distribution with the mean value greater than one. Secondly, an error in the model parameters was simulated with a multiplicative scaling factor sampled from a mean-one normal distribution with a dimensionless standard deviation of 0.2. Since within MISDc the SWB model computes the saturation degree temporal pattern, an error only in its parameters was considered, too. In fact, these parameters are those more variable across catchments and, hence, they are more difficult to be estimated. In all investigated cases, the model was run 1-year before to start with the SWI assimilation (i.e. for the period January 2007-June 2009) so that the effects of the initial conditions for the SWB component can be reduced. It's worth of noting that the selection of the error probability distributions and, mainly, of their standard deviation to perturb the input rainfall along with the model parameters is a critical point in the set up of the synthetic experiments. For this study, we followed the indication by Crow and Ryu (2009) for the selection of the probability distribution, even though different standard deviation values were used. In fact, in a preliminary analysis (not shown here for sake of brevity), we observed that low values of the standard deviation produced results very similar to the real case (without adding errors), whereas high values provided unrealistic results with poor model performance. Therefore, a trade-off between the two extreme conditions was selected for this study. Thirdly, an error in the initial conditions was tackled on starting the model run one month before the occurrence of the first flood event and considering as initial soil wetness condition the whole range of feasible values from zero to one. For all cases, as previously, the model results with and without assimilation were compared and discussed.

To evaluate the efficiency of the assimilation procedure, an efficiency index, Eff, was used (Aubert et al., 2003):

$$
\mathrm{Eff}=100\left[1-\frac{\sum_{t}\left(Q_{\mathrm{ass}}(t)-Q_{\mathrm{obs}}(t)\right)^{2}}{\sum_{t}\left(Q_{\mathrm{sim}}(t)-Q_{\mathrm{obs}}(t)\right)^{2}}\right]
$$

where $t$ is time, $Q_{\text {obs }}$ is the observed discharge, $Q_{\text {sim }}$ and $Q_{\text {ass }}$ are the simulated discharge without and with assimilation, respectively. If Eff is greater than 0 then the assimilation produces an improvement in the runoff simulation by the model.

\section{Results and discussion}

In this section we show the MISDc model calibration, the comparison between the modeled and ASCAT-derived saturation degree and finally the data assimilation results. 
Table 2. - MISDc model performance in flood prediction with modeled, sim., and assimilated, ass., soil moisture and for different runs (R: rainfall, PAR: parameters, IC: initial conditions, $N S$ : Nash-Sutcliffe efficiency index, $\left|\varepsilon_{Q p}\right|$ : absolute error on peak discharge, $\left|\varepsilon_{R d}\right|$ : absolute error on runoff volume, Eff: efficiency index for the assimilation). For the rainfall error a multiplicative factor with mean equal to 1 (unbiased) and 1.1 (biased) is considered. For the analysis with the observed data, the efficiency indices or the differences in the performance indicators with and without assimilation statistically different from zero (at a significance level less than 5\%) are reported in bold.

\begin{tabular}{|c|c|c|c|c|c|c|c|c|c|c|c|c|c|}
\hline \multirow{3}{*}{ Basin } & \multirow{3}{*}{$\begin{array}{l}\text { Index } \\
(\%)\end{array}$} & & & \multicolumn{10}{|c|}{ Synthetic experiment } \\
\hline & & \multicolumn{2}{|c|}{ Observed data } & \multicolumn{2}{|c|}{$\begin{array}{c}\text { R error } \\
(\text { mean }=1)^{*}\end{array}$} & \multicolumn{2}{|c|}{$\begin{array}{c}\text { R error } \\
(\text { mean }=1.1)^{*}\end{array}$} & \multicolumn{2}{|c|}{$\begin{array}{l}\text { PAR } \\
\text { error* }\end{array}$} & \multicolumn{2}{|c|}{$\begin{array}{l}\text { PAR } \\
\text { error*1 }\end{array}$} & \multicolumn{2}{|c|}{$\begin{array}{c}\mathrm{IC} \\
\text { error** }\end{array}$} \\
\hline & & sim. & ass. & sim. & ass. & sim. & ass. & sim. & ass. & sim. & ass. & sim. & ass. \\
\hline \multirow[t]{4}{*}{ NIC } & $N S$ & 75 & 84 & 50 & 69 & -22 & 61 & 37 & 65 & 17 & 68 & 36 & 83 \\
\hline & $\left|\varepsilon_{Q p}\right|$ & 39 & 24 & 42 & 35 & 60 & 34 & 49 & 34 & 49 & 32 & 43 & 18 \\
\hline & $\left|\varepsilon_{R d}\right|$ & 44 & 21 & 44 & 27 & 79 & 41 & 57 & 34 & 67 & 35 & 59 & 24 \\
\hline & Eff & l & 39 & l & 28 & / & 66 & l & 32 & I & 47 & I & 62 \\
\hline \multirow[t]{4}{*}{ ASS } & $N S$ & 62 & 76 & 53 & 68 & -4 & 50 & 46 & 66 & 63 & 76 & 58 & 76 \\
\hline & $\left|\varepsilon_{Q p}\right|$ & 28 & 29 & 35 & 34 & 47 & 34 & 34 & 31 & 29 & 30 & 33 & 30 \\
\hline & $\left|\varepsilon_{R d}\right|$ & 33 & 22 & 35 & 26 & 52 & 29 & 37 & 26 & 33 & 23 & 34 & 22 \\
\hline & Eff & I & 36 & l & 24 & I & 50 & I & 24 & I & 33 & I & 40 \\
\hline \multirow[t]{4}{*}{$\mathrm{CHI}$} & $N S$ & 55 & 72 & 38 & 59 & -16 & 40 & 43 & 63 & 50 & 69 & 42 & 71 \\
\hline & $\left|\varepsilon_{Q p}\right|$ & 28 & 20 & 38 & 34 & 54 & 38 & 34 & 28 & 31 & 24 & 38 & 22 \\
\hline & $\left|\varepsilon_{R d}\right|$ & 33 & 26 & 38 & 34 & 66 & 47 & 40 & 32 & 34 & 29 & 44 & 27 \\
\hline & Eff & l & 44 & I & 32 & l & 48 & I & 29 & l & 33 & l & 49 \\
\hline \multirow[t]{4}{*}{ TEV } & $N S$ & 76 & 78 & 69 & 73 & 75 & 74 & 68 & 71 & 67 & 72 & 71 & 77 \\
\hline & $\left|\varepsilon_{Q p}\right|$ & 42 & 39 & 43 & 40 & 25 & 28 & 40 & 38 & 44 & 41 & 39 & 35 \\
\hline & $\left|\varepsilon_{R d}\right|$ & 19 & 24 & 23 & 25 & 31 & 40 & 28 & 29 & 28 & 27 & 31 & 32 \\
\hline & Eff & I & 5 & I & 7 & I & -3 & I & 6 & I & 12 & I & 12 \\
\hline \multirow[t]{4}{*}{ TIM } & $N S$ & 60 & 63 & 55 & 57 & 32 & 44 & 34 & 43 & 42 & 53 & 27 & 62 \\
\hline & $\left|\varepsilon_{Q p}\right|$ & 48 & 48 & 52 & 48 & 38 & 39 & 46 & 43 & 49 & 47 & 52 & 50 \\
\hline & $\left|\varepsilon_{R d}\right|$ & 18 & 13 & 24 & 21 & 31 & 26 & 33 & 26 & 31 & 25 & 48 & 15 \\
\hline & Eff & I & 8 & I & 4 & I & 11 & I & 7 & I & 7 & I & 41 \\
\hline
\end{tabular}

* mean values for 100 simulations

** mean values for all simulations varying IC from 0 to 1

1 the error was added only for the parameters of the soil water balance model

\subsection{MISDc model calibration}

The rainfall-runoff model MISDc was calibrated for the five investigated catchments considering more than 100 flood events that occurred in the period 2000-2007. In fact, it has to be noticed that the model is able to simulate only flood events (not the continuous discharge time series) because it was developed for this purpose in order to reduce the number of involved parameters as much as possible. Therefore, all the results are shown only for flood events. To investigate the reliability of the MISDc model on flood prediction, different criteria were adopted: the error on peak discharge, $\varepsilon_{Q p}$, and on runoff volume, $\varepsilon_{R d}$, and the Nash-Sutcliffe efficiency index, $N S$. The model results (not shown for sake of brevity) were found to be in good agreement with observed data with median NS higher than $75 \%$ and median absolute error on peak discharge, $\left|\varepsilon_{Q p}\right|$, and runoff volume, $\left|\varepsilon_{R d}\right|$, less than $30 \%$. Then, the model was run for the period for which
ASCAT data are available. This period can consequently be considered as a validation period. Obviously, a limited number of flood events were available for this short period $(\sim 4$ events for each catchment) and, hence, the obtained results have to be considered as preliminary. These results are reported in Table 2 showing a slightly lower accuracy than that obtained during the calibration period (as expected). This is mainly due to the limited magnitude of the flood events observed in the last 2 years and half. More detailed information on the model behaviour and performance in the study area can be also found in Brocca et al. (2010a, c, d).

\subsection{Modeled versus ASCAT-derived saturation degree}

Based on the model results for the period 2008-2009, the saturation degree simulated by the model, $S D_{\text {mod }}$, was used for the assessment of the ASCAT SWI reliability. In particular, for each catchment, the corresponding $S D_{\text {mod }}$ was compared 

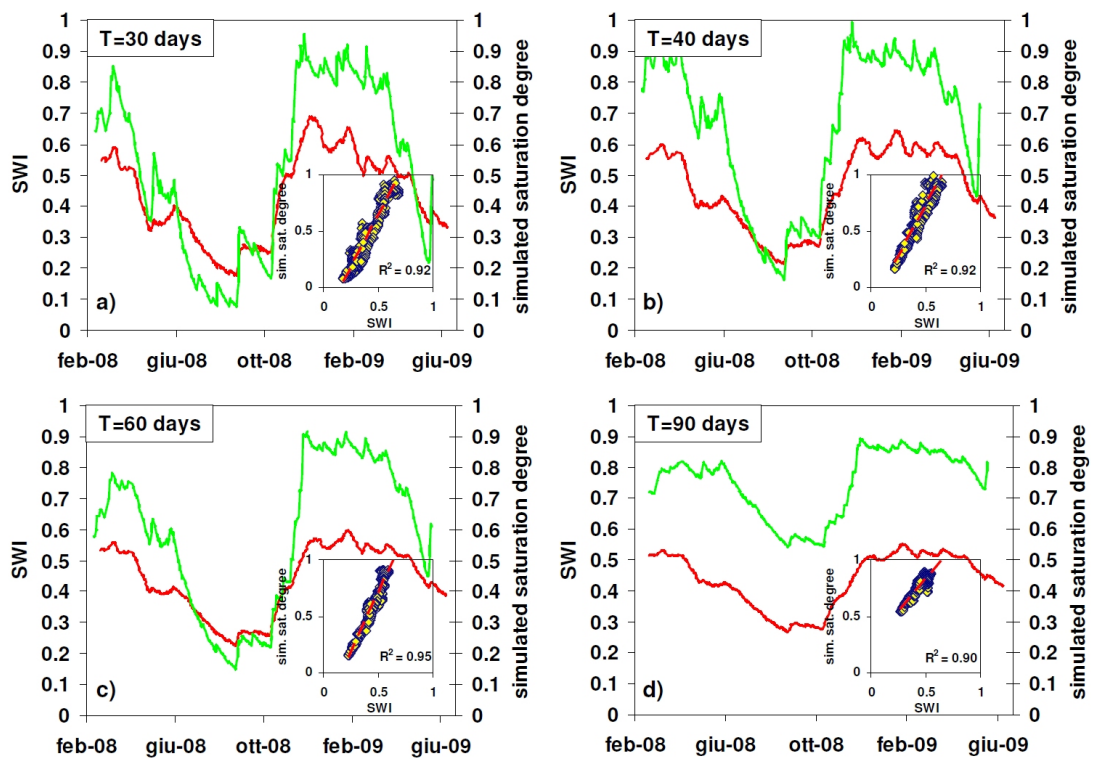

Fig. 2. - ASCAT Soil Wetness Index, SWI, versus simulated saturation degree for (a) TEV, (b) ASS, (c) NIC, and (d) TIM catchments.

with the SWI index derived from the ASCAT pixel closest to the centroids of the catchment itself. The comparison between the SWI and $S D_{\text {mod }}$ is shown in Fig. 2 for four of the investigated catchments.

As it can be inferred from Eq. (1), the computation of SWI requires the calibration of the $T$ parameter, which was carried out by maximizing the determination coefficient, $R^{2}$, between the $S D_{\text {mod. }}$ and SWI time series. According to previous studies (Brocca et al., 2009a; Lacava et al., 2010), $T$ was found ranging between 30 (TEV) and 90 days (TIM). In a physically consistent way, lowest values were obtained for the fast reacting catchments characterized by a thin active soil layer. Accordingly, the soil layer depth used in the rainfall-runoff model was equal to $70,80,120$, and $270 \mathrm{~cm}$ for the TEV, ASS, NIC and TIM catchments, respectively.

As it can be seen in Fig. 2, there is a very good agreement between the temporal pattern of $S D_{\bmod }$ and SWI, with $R^{2}$ higher than 0.90 with a maximum of 0.95 for the NIC catchment. The best performance obtained for NIC catchment might be mainly explained by the dense raingauge network covering it (1 station per $\sim 20 \mathrm{~km}^{2}$, see Table 1) and, hence the high reliability of $S D_{\text {mod. }}$. Moreover, one of its sub-catchment was used to develop and test the SWB model component of MISDc. Therefore, further investigations involving a larger number of catchments with different soil and land use characteristics are needed for validating the procedure. Moreover, the Root Mean Square Error computed between $S D_{\text {mod }}$ and the rescaled SWI, SWI*, was less than 0.046 . Assuming for the soil a porosity equal to 0.30 , this corresponds to an error of less than $0.014 \mathrm{~m}^{3} / \mathrm{m}^{3}$ in volumetric terms. When compared to previous results reported in the scientific literature (e.g. Ceballos et al., 2005; Prigent et al., 2005; Rudiger et al., 2009; Gruhier et al., 2010) for other satellite sensors, the reliability of the ASCAT SWI to estimate the saturation degree temporal pattern can be considered outstanding. The high temporal resolution of the ASCAT sensor could be one important reason for these findings (Pellarin et al., 2006; De Lange et al., 2008; Brocca et al., 2010b). Finally, it has to be noted that when considering a constant $T$ value of 50 days, $R^{2}$ remained greater than 0.83 for all catchments and so, this value might be adequate for ungauged catchments in the study area.

\subsection{Data assimilation}

The rescaled SWI, SWI*, derived through Eq. (3), was directly incorporated into the MISDc by using Eq. (4). For this step, the $G$ parameter was made to vary between 0 (perfect model) and 1 (perfect observation). Fig. 3a shows the value of the Nash-Sutcliffe efficiency index, $N S$, versus the $G$ parameter for all the investigated catchments. Overall, it is evident that the assimilation of remotely sensed saturation degree estimates can only improve the model performance as can be already inferred for $G>0.2$ for NIC, ASS and CHI catchments; whereas for TEV and TIM the assimilation did not make worse the model performance. However, by inspecting in depth Fig. 3a, an optimal $G$ value (i.e. maximizing the $N S$ index) can be found, on average, equal to 0.2 ; while ranging between 0.01 (TEV) and 0.40 (CHI), with higher values when the added-value of the saturation degree observations was more substantial. According to Eq. (5), a gain parameter equal to 0.2 means that the model error, $\sigma_{S D_{\text {mod }}}$, is half of the satellite one. Similar results were obtained by attempting to reproduce saturation degree observations with a satellite and soil water balance model (Pellarin et al., 2006; Rudiger et al., 2009) applied to the region of the present study (Brocca et al., 2008, 2009a), giving also a physical explanation to the obtained $G$ values. 

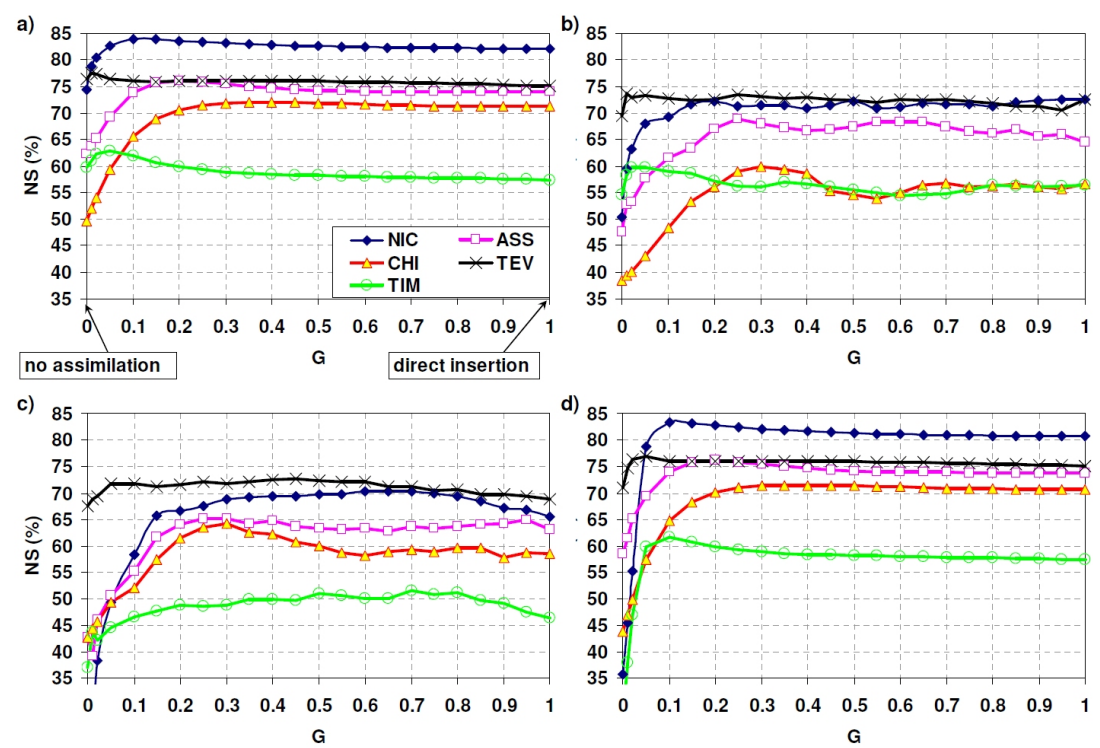

Fig. 3. - Nash-Sutcliffe efficiency index, NS, versus the Gain parameter, G, for all the investigated catchments: (a) observed data, (b) unbiased rainfall error, (c) MISDc parameters error, and (d) initial conditions error.

The results of the data assimilation procedure in terms of model performance, using the optimal $T$ value for each catchment, are shown in Table 2; Fig. 4 shows, by way of example, the simulated saturation degree for the NIC and ASS catchments (with and without SWI* assimilation) along with the observed and simulated discharge for the flood events which occurred in the study period. For these two catchments satisfactory results were derived with the assimilation; the NS coefficient increased from 75 and $62 \%$ to 84 and $76 \%$ for the NIC and ASS catchments, respectively. In addition, $\left|\varepsilon_{R d}\right|$ was reduced by 50 and $33 \%$ for the two catchments, respectively, corroborating the added-value of ASCAT assimilation. In fact, since the assimilation modifies the initial wetness conditions, a major effect on total runoff instead of runoff peak estimation was expected. In addition, a classical bootstrap procedure (Wang et al., 2008) was applied to assess if the efficiency indices and the differences in the performance indicators $\left(N S,\left|\varepsilon_{R d}\right|,\left|\varepsilon_{Q p}\right|\right)$ with and without assimilation are statistically different from zero at a significance level less than 5\%. Specifically, 5000 re-sampling of the efficiency indices and of the differences in the performance indicators, each one obtained by random sampling with replacement from the original dataset, were derived and from the corresponding samples the confidence intervals were computed. As shown in Table 2, the efficiency index is different from zero at the 5\% significance level for all catchments, whereas the differences in $N S$ and $\left|\varepsilon_{R d}\right|$ are significant only for NIC, ASS and CHI catchments. These results are clearly tied to the low number of flood events investigated in this study, of course an analysis for a longer period should provide more general findings. It has to be noted that the bootstrap analysis was not carried out for the synthetic experiments for which more than one simulation were done.
To better visualize the effects of the assimilation of ASCAT on the model simulation, Fig. 5 shows the cumulated runoff for the observed and the simulated data with and without SWI* assimilation for all investigated catchments. As it can be seen, for the three smaller catchments $\left(<150 \mathrm{~km}^{2}\right)$ the improvements related to SWI* assimilation are evident whereas results are quite similar for the other two catchments (TEV and TIM). The same figures can be derived looking at the values of the efficiency index, Eff, that range between 36 and $44 \%$ for the three smallest catchments and are less than $8 \%$ for the two largest ones.

\subsection{Synthetic experiments}

In order to better analyze the counterintuitive results previously obtained (better results for small catchments assimilating coarse resolution satellite data), three synthetic experiments were conducted. The target is to check if the remotely sensed SWI* assimilation can counterbalance a wrong estimation of saturation degree due to errors on rainfall, model parameters or initial soil wetness conditions.

For the synthetic experiments, both the re-computation of SWI* and of the $G$ parameter should be carried out. However, in the study, it is assumed that the parameters used for the SWI* computation were obtained by a previous analysis (for "non perturbed" conditions) and that the errors occur only after the calibration period when $\mathrm{SWI}^{*}$ was assimilated. For that, only the variations of the $G$ parameter is considered here. It's worth of noting that the synthetic experiments are aimed at analyzing the SWI* potential for "perturbed" operational conditions that might occur as, for instance, rainfall errors due to a temporary malfunctioning of the monitoring network or wrong model parameterization for a calibration 

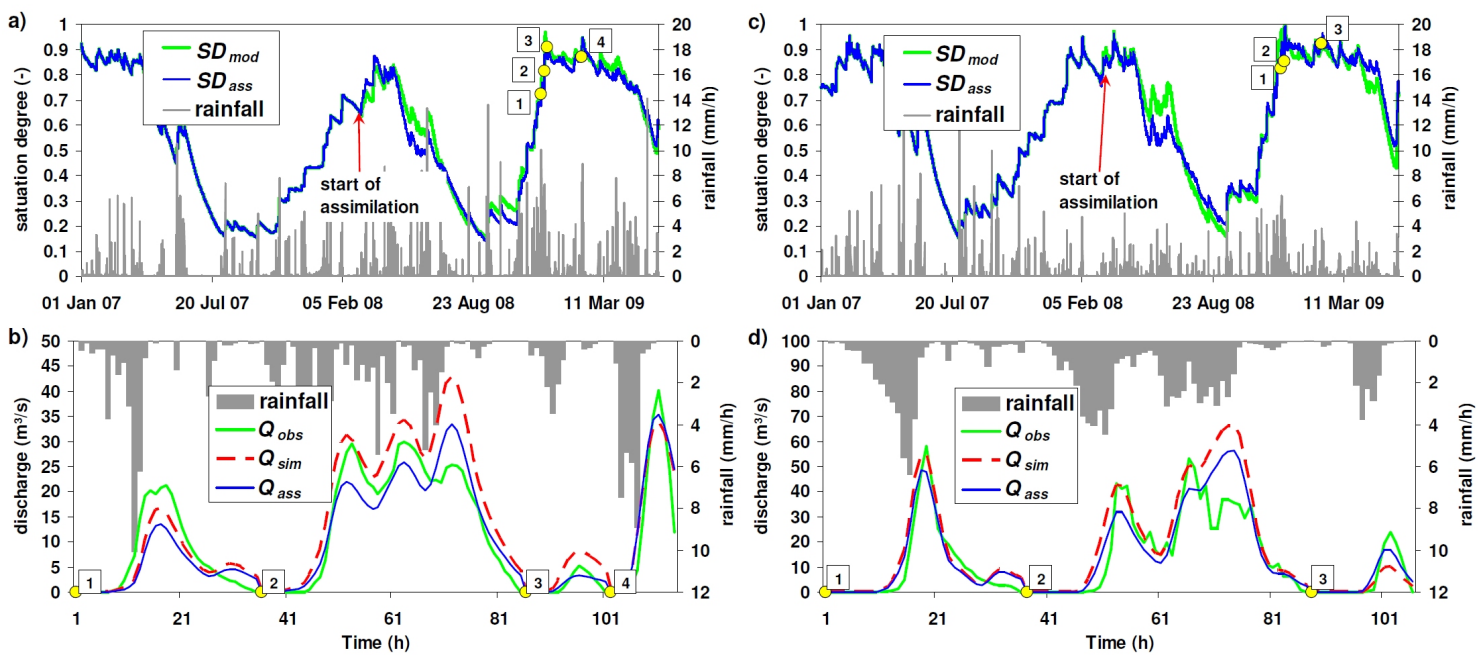

Fig. 4. - Results with and without ASCAT SWI* assimilation for the NIC (a, b) and ASS (c, d) catchment in the period Janary 2007-June 2009: (a, c) observed rainfall and simulated saturation degree; (b, d) observed versus simulated discharge for the sequence of the most significant flood events occurred in the period.
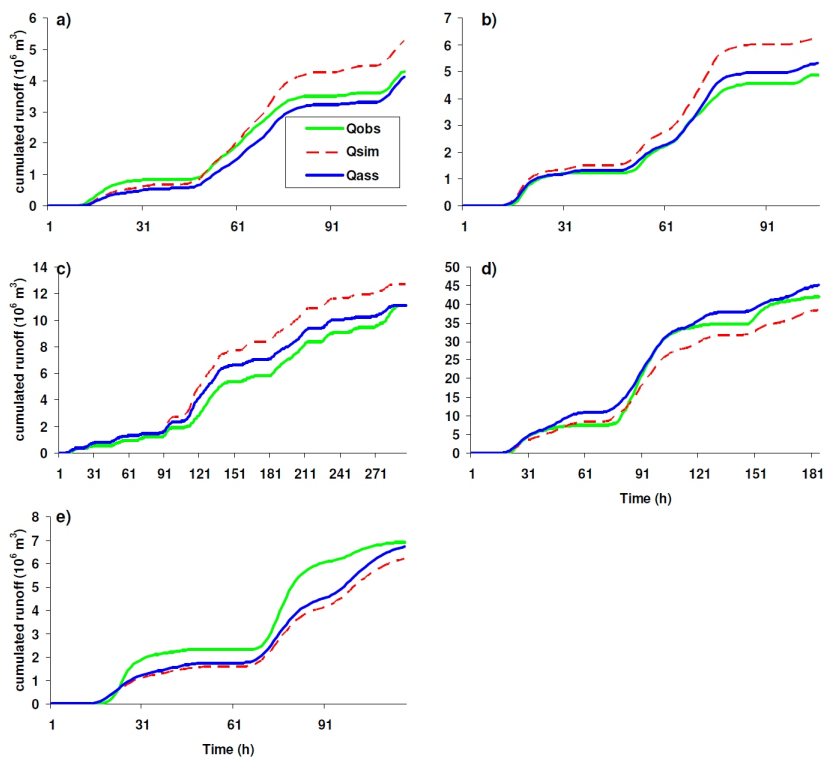

Fig. 5. - Cumulated runoff for the observed and simulated data with and without ASCAT SWI* assimilation for: (a) NIC, (b) ASS, (c) $\mathrm{CHI}$, (d) TEV and (e) TIM catchments.

period not representative of the full range of possible conditions, e.g. dry period. Specifically, Fig. 3b-d show the $N S$ values versus the $G$ parameter for all the investigated catchments and for all the synthetic experiments; Table 2 shows only the corresponding results by using a fixed $G$ value equal to that obtained for the analysis with the observed data.

For the first two synthetic experiments, as previously described, a random multiplicative error on rainfall and MISDc parameters was considered. For each catchment, 100 sim- ulations were carried out in order to minimize the effects related to randomisation. For both experiments, the increase in model performance due to the $\mathrm{SWI}^{*}$ assimilation was reduced (see Table 2). On average, the Eff index decreased from $25.6 \%$ to $17.2 \%$ and $18.8 \%$ when rainfall and model parameter errors were considered, respectively. Similar findings were obtained analyzing the other performance indices. It is clear that the error on rainfall and model parameters affected the results significantly. This fact can explain the lower advantages of SWI* assimilation observed for the two larger catchments, where higher uncertainties on model structure suitability (lumped model parameterization) and rainfall pattern identification arise. However, further and more detailed analyses should be carried out to validate this hypothesis. Figure 6 shows the results for these two synthetic experiments applied to the $\mathrm{CHI}$ catchment. The three flood events for which a higher added-value was obtained with SWI* $^{*}$ assimilation are highlighted (square box). In particular, these events occurred in the transition period between the dry (summer) and wet (winter) saturation degree conditions for which the SWI* assimilation proved to be more valuable. This aspect has to be emphasized because the differences in runoff response for a given rainfall event can be remarkable, in particular for Mediterranean catchments where the seasonal soil moisture temporal pattern is highly pronounced (see e.g. Latron et al., 2009). Moreover, during intermediate wetness conditions, runoff predictability is strongly reduced (Zehe and Bloschl, 2004) and, hence, the improvement deriving from the assimilation of ASCAT data can be highly significant.

It has to be noted that when a bias error was exploited to perturb the rainfall time series (as it can occur when satellite or radar rainfall estimates were adopted), the improvement 

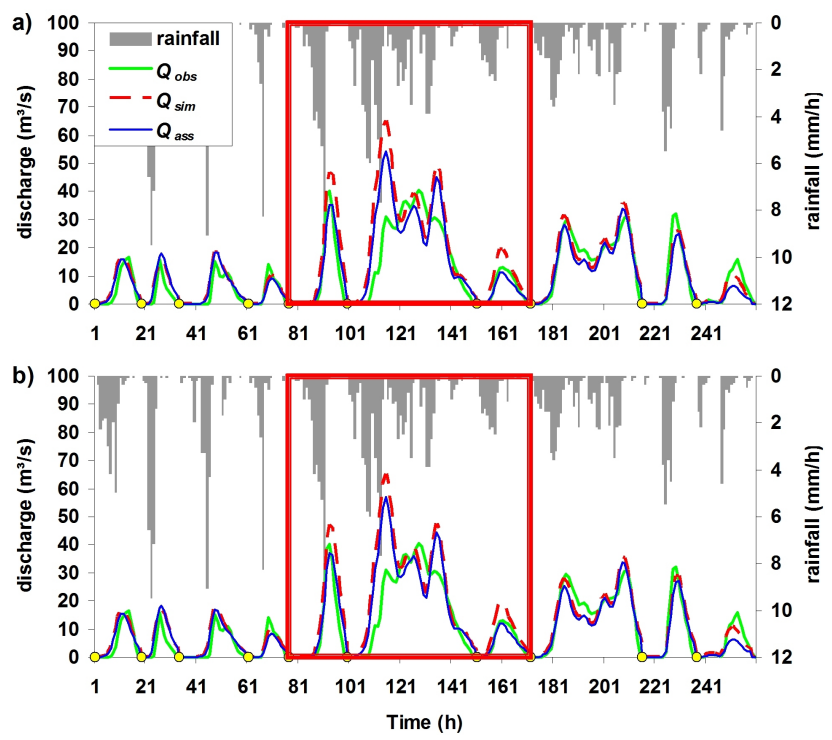

Fig. 6. - Sequence of the simulated flood events with and without ASCAT SWI* assimilation for the CHI catchment in the period January 2007-June 2009 and considering an unbiased error on: (a) rainfall, and (b) model parameters. The simulated and assimilated discharge represents the average of 100 model runs.

due to SWI* assimilation is more evident. For instance, considering a multiplicative scaling factor with mean equal to 1.1, the Eff score for the NIC catchment increased up to $66 \%$. This is also because MISDc tends to overestimate discharge for this particular catchment (see Fig. 5). Similar results were obtained also for the other two catchments, where an overestimation of discharge by MISDc was observed (see Table 2). On average, the efficiency index was found equal to $55 \%$ for these three catchments (NIC, ASS and CHI) and only 4\% for the remaining two (even a negative efficiency value was found for TEV catchment). As far as the error in model parameters is concerned, if only those included in the SWB model are considered, results become more similar to the ones of the normal data assimilation run (see Table 2) with average Eff equal to $26 \%$. All the results obtained through these two synthetic experiments highlight the importance of knowing what could be the source of error when data assimilation findings have to be evaluated. In fact, to understand the results of the data assimilation even for other rainfallrunoff models, satellite sensors or climatic regions, a clear separation of the different error sources has to be investigated. Finally, looking at the influence of the $G$ parameter on the assimilation performances for these two experiments (Fig. 3b-c), results are quite similar to those obtained with the observed data with an obvious decrease in the model performance. In particular, for $G$ values between 0.25 and 0.50 , a significant increase in runoff prediction accuracy was observed for all catchments if compared to the results without assimilation $(G=0)$.
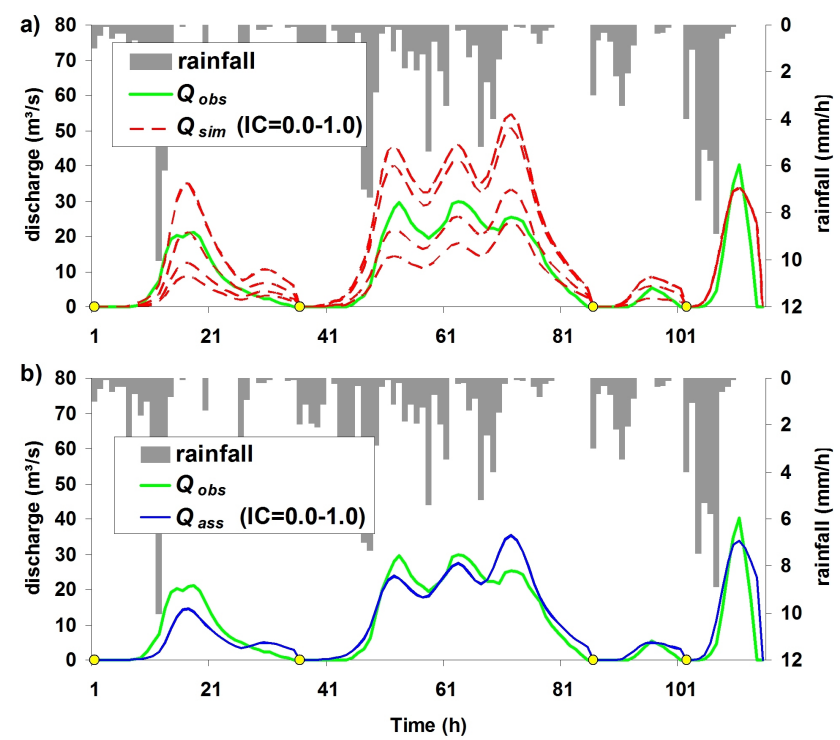

Fig. 7. - Sequence of the simulated flood events for the NIC catchment in the period November 2008-June 2009 assuming unknown initial soil wetness conditions, IC: (a) without, and (b) with ASCAT SWI* assimilation.

More of interest from the practical and operational point of view is the third synthetic experiment that assumes uncertainties on the model initial conditions. This situation frequently occurs in practice when a continuous time series of the forcing data (rainfall and temperature) is not available because of, for instance, sensor failures, interruptions in the data transmission or errors in real-time data. As expected, in this case the data assimilation furnished a decisive improvement in model performance for all investigated catchments (see Table 2), even though a non-optimal $G$ value was used (Fig. 3d). For instance, Fig. 5 shows the results obtained for the NIC catchment when SWI* was assimilated. MISDc simulations are very similar to those obtained without uncertain initial conditions. Obviously, these results depend on a series of factors including the time in which the initial conditions are set (summer, winter, transition period) and the length and the climatic conditions of the period between the start of the model run and the first flood event. However, these findings are very encouraging for an efficient use of satellite information within operational systems of real-time flood forecasting which frequently rely on event-based rainfall-runoff models and require a strict and accurate estimation of the soil moisture initial conditions (Berthet et al., 2009).

\section{Conclusions}

A first investigation of the potential of the ASCAT derived saturation degree product for hydrological applications was conducted. Two main outcomes can be derived from the performed analyses: 
1. SWI, the soil wetness index derived from ASCAT, was found strongly correlated with the simulated saturation degree, with determination coefficients $\left(R^{2}\right)$ higher than 0.90 and RMSE values less than $0.014 \mathrm{~m}^{3} / \mathrm{m}^{3}$.

2. The assimilation of the rescaled SWI (denoted SWI*) into the MISDc rainfall-runoff model furnished an evident improvement of the model performance, especially when initial soil wetness conditions were unknown.

These results support the introduction of the ASCATderived saturation degree estimates into an operational system for real-time flood forecasting (Brocca et al., 2010c). However, further and more detailed analysis is needed to confirm these results. A more comprehensive data assimilation technique (e.g. ensemble Kalman filter or particle filter), a longer time period and a larger number of catchments have to be used for a more robust test of the proposed procedure. Moreover, a different structure for the rainfall-runoff model should be investigated as well. In particular, the introduction of a thin surface layer might allow to directly assimilate the surface soil moisture values retrieved by using remote sensing, without needing of a method which provides profile soil moisture values (such as the exponential filter used in this study).

Acknowledgements. The authors wish to thank R. Rosi for his technical assistance. They are also grateful to the Region of Umbria for providing most of the analyzed data. This work was partly funded by the "EUMETSAT Satellite Application Facility on Support to Operational Hydrology and Water Management (H-SAF)" project established by EUMETSAT.

Edited by: D. F. Prieto

\section{References}

Albergel, C., Rüdiger, C., Carrer, D., Calvet, J. C., Fritz, N., Naeimi, V., Bartalis, Z., and Hasenauer, S.: An evaluation of ASCAT surface soil moisture products with in-situ observations in southwestern France, Hydrol. Earth Syst. Sci., 13, 115-124, 2009.

Anctil, F., Lauzon, L., and Filion, M.: Added gains of soil moisture content observations for streamflow predictions using neural networks, J. Hydrol., 359(3-4), 225-234, 2008.

Aubert, D., Loumagne, C., and Oudin, L.: Sequential assimilation of soil moisture and streamflow data in a conceptual rainfall runoff model, J. Hydrol., 280, 145-161, 2003.

Bartalis, Z., Wagner, W, Naeimi, V., Hasenauer, S., Scipal, K., Bonekamp, H., Figa, J., and Anderson, C.: Initial soil moisture retrievals from the METOP-A Advanced Scatterometer (ASCAT), Geophys. Res. Lett., 34, L20401, doi:10.1029/2007GL031088, 2007.

Beck, H. E., de Jeu, R. A. M., Schellekens, J., van Dijk, A. I. J. M., and Bruijnzeel, L. A: Improving Curve Number based storm runoff estimates using soil moisture proxies, IEEE J. Sel. Top. Appl., 2(4), 1939-1404, 2010.
Berthet, L., Andréassian, V., Perrin, C., and Javelle, P.: How crucial is it to account for the Antecedent Moisture Conditions in flood forecasting? Comparison of event-based and continuous approaches on 178 catchments, Hydrol. Earth Syst. Sci., 13, 819831, 2009.

Brocca, L., Melone, F., and Moramarco, T.: On the estimation of antecedent wetness condition in rainfall-runoff modelling, Hydrol. Process., 22(5), 629-642, 2008.

Brocca, L., Melone, F., Moramarco, T., and Morbidelli, R.: Antecedent wetness conditions estimation based on ERS scatterometer data, J. Hydrol, 364(1-2), 73-87, 2009a.

Brocca, L., Melone, F., Moramarco, T., and Singh, V.P.: Assimilation of observed soil moisture data in storm rainfall-runoff modelling, J. Hydrol. Engng. ASCE, 14(2), 153-165, 2009b.

Brocca, L., Barbetta, S., Melone, F., and Moramarco, T.: A continuous rainfall-runoff model derived from investigations on a small experimental basin. IAHS Red Book Series: Status and Perspectives of Hydrology in Small Basins, IAHS Publ. 336, 179-185, 2010a.

Brocca, L., Melone, F., Moramarco, T., Wagner, W., and Hasenauer, S.: ASCAT soil wetness index validation through in-situ and modeled soil moisture data in central Italy, Remote Sens. Environ., 114(11), 2745-2755, 2010b.

Brocca, L., Melone, F., Moramarco, T., Wagner, W., Hasenauer, S., and Berni, N.: Use of ASCAT derived soil moisture product for real-time flood forecasting in the Upper Tiber river, Geophys. Res. Abstr., 12, EGU2010-4634-1, 2010c.

Brocca, L., Melone, F., and Moramarco, T.: Coupling a soil water balance and an event-based rainfall-runoff model for flood frequency estimation and real time flood forecasting, Hydrol. Process., under review, $2010 \mathrm{~d}$.

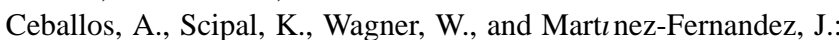
Validation of ERS Scatterometer-Derived Soil Moisture Data in the Central Part of the Duero Basin, Spain, Hydrol. Process., 19, 1549-1566, 2005.

Chow, V. T., Maidment, D. R., and Mays, L. W.: Applied Hydrology. McGraw-Hill, New York, 1998.

Crow, W. T. and Ryu, D.: A new data assimilation approach for improving runoff prediction using remotely-sensed soil moisture retrievals, Hydrol. Earth Syst. Sci., 13, 1-16, 2009.

Crow, W. T., Bindlish, R., and Jackson, T. J.: The added value of spaceborne passive microwave soil moisture retrievals for forecasting rainfall-runoff ratio partitioning, Geophys. Res. Lett., 32, L18401, doi:10.1029/2005GL023543, 2005.

De Lange, R., Beck, R., van de Giesen, N., Friesen, J., de Wit, A., and Wagner, W.: Scatterometer-derived soil moisture calibrated for soil texture with a one-dimensional water-flow model, IEEE T Geosci. Remote, 46(12), 4041-4049, 2008.

Entekhabi, D. E., Njoku, P., O’Neill, T., Jackson, J., Thomas, J., Entin, J., and Eastwood, I.: The Soil Moisture Active/Passive Mission (SMAP), Eos Trans. AGU, 88(52), Abstract H33I-01, 2008.

Francois, C., Quesney, A., and Ottle, C.: Sequential assimilation of ERS-1 SAR data into a coupled land surface-hydrological model using an extended Kalman filter, J. Hydrometeorol., 4(2), 473487, 2003.

Goodrich, D. C., Schmugge, T. J., Jackson, T. J., Unkrich, C. L., Keefer, T. O., Parry, R., Bach, L. B., and Amer, S. A.: Runoff simulation sensitivity to remotely sensed initial soil water con- 
tent, Water Resour. Res., 30(5), 1393-1406, 1994.

Gruhier, C., de Rosnay, P., Hasenauer, S., Holmes, T., de Jeu, R., Kerr, Y., Mougin, E., Njoku, E., Timouk, F., Wagner, W., and Zribi, M.: Soil moisture active and passive microwave products: intercomparison and evaluation over a Sahelian site, Hydrol. Earth Syst. Sci., 14, 141-156, 2010.

Huang, M., Gallichand, J., Dong, C., Wang, Z., and Shao, M.: Use of soil moisture data and curve number method for estimating runoff in the Loess Plateau of China, Hydrol. Process., 21(11), 1471-1481, 2007.

Jacobs, J. M., Myers, D. A., and Whitfield, B. M.: Improved rainfall/runoff estimates using remotely sensed soil moisture, J Am. Water Resour. As., 4, 313-324, 2003.

Kerr, Y. H., Waldteufel, P., Wigneron, J. P., Martinuzzi, J., Font, J., and M. Berger: Soil moisture retrieval from space: the Soil Moisture and Ocean Salinity (SMOS) mission, IEEE T Geosci. Remote, 39, 1729-1735, 2001.

Koren, V., Moreda, F., and Smith, M.: Use of soil moisture observations to improve parameter consistency in watershed calibration, Phys. Chem. Earth, 33(17-18), 1068-1080, 2008.

Lacava, T., Brocca, L., Calice, G., Melone, F., Moramarco, T., Pergola, N., and Tramutoli V.: Soil moisture variations monitoring by AMSU-based soil wetness indices: a long-term intercomparison with ground measurements, Remote Sens. Environ., 114(10), 2317-2325, 2010.

Latron, J., Llorens, P., and Gallart, F.: The Hydrology of Mediterranean Mountain Areas, Geography Compass, 3/6, 2045-2064, 2009.

Longobardi, A., Villani, P., Grayson, R. B., and Western, A. W.: On the relationship between runoff coefficient and catchment initial conditions. Proc., MODSIM 2003 International Congress on Modelling and Simulation, Modelling and Simulation Society of Australia and New Zealand Inc., Townsville, Australia, 2, 867872, 2003.

Loumagne, C., Normand, M., Riffard, M., Weisse, A., Quesney, A., Le Hegarat-Mascle, S., and Alem, F.: Methodology for integration of remote sensing data into hydrological models for reservoir management purposes. Hydrol. Sci. J., 46(1), 89-102, 2001.

Matgen, P. J., Henry, B., Hoffmann, L., and Pfister, L.: Assimilation of remotely sensed soil saturation levels in conceptual rainfallrunoff models. IAHS Red Book Series: Prediction in Ungauged Basins : Promise and Progress, IAHS Publ., 303, 226-234, 2006.

Maybeck, P. S.: Stochastic models, estimation, and control. Vol. 1. Academic Press, New York, USA, 1-16, 1979.

Merz, R. and Bloschl, G.: A regional analysis of event runoff coefficients with respect to climate and catchment characteristics in Austria, Water Resour. Res., 45, W01405, doi:10.1029/2008WR007163, 2009.

Meyles, E., Williams, A., Ternan, L., and Dowd, J.: Runoff generation in relation to soil moisture patterns in a small Dartmoor catchment, Southwest England, Hydrol. Process., 17, 251-264, 2003.

Naeimi, V., Scipal, K., Bartalis, Z., Hasenauer, S., and Wagner, W.: An improved soil moisture retrieval algorithm for ERS and METOP scatterometer observations, IEEE T Geosci. Remote, 47(7), 1999-2013, 2009.

Parajka, J., Naemi, V., Bloschl, G., and Komma, J.: Matching ERS scatterometer based soil moisture patterns with simulations of a conceptual dual layer hydrologic model over Austria, Hydrol.
Earth System Sci., 13, 259-271, 2009.

Parajka, J., Naeimi, V., Blöschl, G., Wagner, W., Merz, R., and Scipal, K.: Assimilating scatterometer soil moisture data into conceptual hydrologic models at the regional scale, Hydrol. Earth Syst. Sci., 10, 353-368, doi:10.5194/hess-10-353-2006, 2006.

Pauwels, R. N., Hoeben, R., Verhoest, N. E. C., De Troch, F. P., and Troch, P. A.: Improvements of TOPLATS-based discharge predictions through assimilation of ERS-based remotely-sensed soil moisture values, Hydrol. Process., 16, 995-1013, 2002.

Pauwels, V. R. N., Hoeben, R., Verhoest, N. E. C., and DeTroch, F. P.: The importance of the spatial patterns of remotely sensed soil moisture in the improvement of discharge predictions for small scale basins through data assimilation, J. Hydrol., 251, 88-102, 2001.

Pellarin, T., Calvet, J. C., and Wagner, W.: Evaluation of ERS scatterometer soil moisture products over a half-degree region in southwestern France, Geophys. Res. Lett., 33, L17401, doi:10.1029/2006GL027231, 2006.

Pfister, L., Drogue, G., El Idrissi, A., Humbert, J., Iffly, J. F., Matgen, P., and Hoffmann, L.: Predicting peak discharge through empirical relationships between rainfall, groundwater level and basin humidity in the Alzette river basin (Grand-Duchy of Luxembourg), J. Hydrol. Hydromech., 51, 210-220, 2003.

Prigent, C., Aires, F., Rossow, W. B., and Robock A.: Sensitivity of satellite microwave and infrared observations to soil moisture at a global scale: Relationship of satellite observations to in situ soil moisture measurements, J. Geophys. Res., 110, D07110, doi:10.1029/2004JD005087, 2005.

Rudiger, C., Calvet, J. C., Gruhier, C., Holmes, T. R. H., de Jeu, R. A. M., and Wagner, W.: An intercomparison of ERS-Scat and AMSRE soil moisture observations with model simulations over France, J. Hydrometeorol., 10(2), 431-447, 2009.

Scipal, K., Drusch, M., and Wagner W.: Assimilation of a ERS scatterometer derived soil moisture index in the ECMWF numerical weather prediction system, Adv. Water Resour., 31, 1101-1112, 2008.

Sinclair, S. and Pegram G. G. S.: A comparison of ASCAT and modelled soil moisture over South Africa, using TOPKAPI in land surface mode, Hydrol. Earth Syst. Sci., 14, 613-626, 2010.

Tramblay, Y., Bouvier, C., Martin, C., Didon-Lescot, J. F., Todorovik, D., and Domergue, J. M.: Assessment of initial soil moisture conditions for event-based rainfall-runoff modelling, J. Hydrol., 380(3-4), 305-317, 2010.

Vereecken, H., Huisman, J. A., Bogena, H., Vanderborght, J., Vrugt, J. A., and Hopmans, J. W.: On the value of soil moisture measurements in vadose zone hydrology: a review, Water Resour. Res., 44, W00D06, doi:10.1029/2008WR006829, 2008.

Wagner, W., Lemoine, G., and Rott, H.: A method for estimating soil moisture from ERS scatterometer and soil data, Remote Sens. Environ., 70, 2, 191-207, 1999a.

Wagner, W., Lemoine, G., Borgeaud, M., and Rott, H.: A study of vegetation cover effects on ERS scatterometer data, IEEE T Geosci. Remote, 37(2), 938-948, 1999b.

Wagner, W., Noll, J., Borgeaud, M., and Rott, H.: Monitoring soil moisture over the Canadian Prairies with the ERS scatterometer, IEEE T Geosci. Remote, 37, 1, 206-216, 1999c.

Wang, C., Zuo, Q., and Zhang, R.: Estimating the necessary sampling size of surface soil moisture at different scales using a random combination method., J. Hydrol., 352(3-4), 309-321, 2008. 
Wooldridge, S. A., Kalma, J. D., and Walker, J. P.: Importance of soil moisture measurements for inferring parameters in hydrologic models of low-yielding ephemeral catchments, Environ. Modell. Softw., 18(1), 35-48, 2003.

Zehe, E. and Bloschl, G.: Predictability of hydrologic response at the plot and catchment scales: role of initial condition, Water Resour. Res., 40(10), W10202, doi:10.1029/2003WR002869, 2004.
Zehe, E., Graeff, T., Morgner, M., Bauer, A., and Bronstert, A.: Plot and field scale soil moisture dynamics and subsurface wetness control on runoff generation in a headwater in the Ore mountains, Hydrol. Earth System Sci., 14, 873-889, 2010. 